\title{
Infant Heart Rate Response to Trigeminal Airstream Stimulation: Determination of Normal and Deviant Values
}

\author{
L. GREGORY ALLEN," \\ RICHARD L. WEAVER \\ Department of Neurology, Section of Pediatric Neurology, Bowman Gray School of Medicine, Wake Forest \\ Universily, Winston-Salem. North Carolina, USA
}

\begin{abstract}
Summary
In this study, trigeminal airstream stimulation is used on a group of normal, sleeping infants to screen for reflex bradycardia. Infants were tested at 1-3 days and at $4,8,12$, and 16 weeks of age. The usual heart rate response was acceleration above the prestimulus level. The amount of heart rate change was seen to depend on prestimulus rate and, to a lesser extent, postconceptional age. Multiple regression analysis of the data provided estimates of expected responses, given postconceptional age and prestimulus heart rate. From these, ranges were established for classification of normal or abnormal responses. Six deviant data points over 2 SDs Irom expected values were identified. Two of these represented heart rate increases and four were heart rate decreases. One deviant heart rate decrease was over 3 SDs from the mean. Although the deviant increases were thought to represent exaggerated startles, the more severe heart rate decreases were believed to be a reflex resembling the diving reflex.
\end{abstract}

\section{Speculation}

Trigeminal airstream stimulation in infants is a method of screening for the existence of a reflex bradycardia which resembles that of a diving reflex. Such a method may be used to identify infants with abnormal response patterns who could, in theory, be at risk for sudden infant death syndrome (SIDS). Use of this method in large groups of normal infants, infants with speciffc pathologic states, and in both sleep stages would yield valuable information about such reflex bradycardia.

The diving or oxygen-conserving reflex is a brainstem-mediated physiologic mechanism found in many vertebrates, which allows for the conservation of available oxygen and the protection of brain neurons during prolonged underwater excursions. The afferent arc of the reflex consists of the ophthalmic and maxillary branches of the trigeminal nerve which supplies the area of the nose and eyes (2). The efferent arc of the reflex is the vagus nerve and the sympathetic system (5). The diving reflex is initiated by cold, wet stimulation of the area around the nose and eyes. Physiologic changes include peripheral vasoconstriction, bradycardia, and apnea. The peripheral vasoconstriction results in reduced blood flow to areas less prone to damage from hypoxia while adequate blood flow is maintained to heart and brain tissues. The diving bradycardia results in a decrease in oxygen consumption during the dive while reflex apnea prevents aspiration (l).

In 1966, Wolf (11) described the bradycardia of the diving reflex in man and speculated that, in a hyperactive state, such a reflex may contribute to sudden death in stuations such as swimming pool deaths, deaths from fright, voodoo deaths, and SIDS. Our report is concerned with the latter, SIDS. In 1972, French $e t$ al. (3) demonstrated physiologic adjustments resembling the diving reflex in infant monkeys upon application of a cold, wet stimulus to the nasal area. We have previously reported the use of trigeminal airstream stimulation in infants as a method of eliciting bradycardia and apnea resembling a dive reflex $(7,10)$. In this study we investigate the extstence of such a reflex bradycardia in normal term neonates and infants.

\section{MATERIALS AND METHODS}

Thirty-four normal newborns were admitted to the study after parental consent was obtained. Infant selection was based on a history of: 1) uncomplicated labor and delivery, and 2) no clinical problems in the neonatal period. A description of the infant population, including Apgar scores, race, sex, gestational age, and birth weight, is shown in Table 1.

Infants were tested at the following ages: less than 1 week (1-3 days) and $4,8,12$, and 16 weeks. While judged to be asleep (quiet, with eyes closed), the following physiologic variables were recorded on a Grass model 7 polygraph (12): EKG from chest leads, respiration by abdominal strain gauge, and heart rate which was taken from the EKG using a Grass tachograph preamplifier. Various chart speeds $(10,15$, or $25 \mathrm{~mm} / \mathrm{sec})$ were used. Table 2 illustrates the number of sleeping infants tested at each age.

The first recording session for each child took place in a room adjoining the intermediate care nursery. Follow-up sessions were conducted in a room in the EEG lab. Infants were either laid on a stretcher or were held by a parent during the testing. On occasions, the child's arms were lightly held or restrained in order to prevent excess startle.

Stimuli presented were short 2 -sec streams of air at $25^{\circ}$. The flow rate was 15 liters/min. Stimuli were delivered through a length of flexible plastic tubing with an interior diameter of $4 \mathrm{~mm}$. The stimulus was presented to the inside of the nostrils from a distance of about $1 \mathrm{~cm}$. Air source was the hospital air system. Each stimulus presentation was simultaneously recorded on the polygraph tracing by a handheld event marker. Five stimuli were given, one at the beginning of every $30-\mathrm{sec}$ epoch. leaving an intertrial interval of approximately $28 \mathrm{sec}$.

The following measurements were recorded for each trial: 1) prestimulus heart rate (preHR): a 2-sec average heart rate in beats per minute taken immediately before stimulus onset, and 2) two measurements of poststimulus heart rate (postHR): postHR 0-2: the average heart rate in beats per minutes for the 2 -sec period immediately after stimulus onset, and post HR 2-4: the average heart rate for the period from $2-4 \mathrm{sec}$ after stimulus onset.

Statistical analysis was directed toward establishing "normal" ranges of heart rate response at varying preHR levels and ages. To reduce the effect of sampling variation, the five readings on preHR and postHR were averaged. 
Table I. Infant population

\begin{tabular}{crr}
\hline A. Sex and race & & \\
\hline Race & F & M \\
\hline N & 4 & 1 \\
C & 10 & 19
\end{tabular}

B. Gestational age

\begin{tabular}{cc} 
Weeks & $n$ \\
\hline 37 & 2 \\
38 & 4 \\
39 & 2 \\
40 & 6 \\
$4 !$ & 15 \\
42 & 3 \\
43 & 1 \\
44 & 1
\end{tabular}

C. Birth Weight

\begin{tabular}{cc}
\hline Grams & $n$ \\
\hline $2000-2499$ & 1 \\
$2500-2999$ & 7 \\
$3000-3499$ & 13 \\
$3500-3999$ & 9 \\
$4000-4499$ & 3 \\
$4500-5000$ & 1
\end{tabular}

D. Apgar scores

\begin{tabular}{ccc}
\hline Scores & I min & 5 min \\
\hline 5 & 2 & 0 \\
6 & 0 & 0 \\
7 & 1 & 0 \\
8 & 8 & 1 \\
9 & 18 & 6 \\
10 & 5 & 27 \\
\hline
\end{tabular}

Table 2. Number of infants tested at each session

\begin{tabular}{cccccc}
\hline & \multicolumn{7}{c}{ Age (weeks) } & & \\
& $<1$ & 4 & 8 & 12 & 16 \\
\hline No. & 34 & 24 & 24 & 16 & 12 \\
\hline
\end{tabular}

Multiple regression was employed to establish the expected response in: I) absolute change in heart rate for both the postHR 0-2- and postHR 2-4-sec intervals, and 2) the percentage of change in heart rate for both the postHR 0-2- and postHR 2-4$\mathrm{sec}$ intervals. The following variables were considered as possible predictors of these heart rate responses: sex, race, Apgar scores (1 and $5 \mathrm{~min}$ ), birth weight, preHR, gestational age, postnatal age, and postconceptional age (gestational plus posinatal age). Sleep stage (active or quiet) was not considered as a variable. Using this approach, abnormal responses may then be easily identified by selecting readings with unexpectedly large differences between observed and expected readings. This provides a system by which observed responses may be compared to a norm.

\section{RESULTS}

Data analysis was performed on 110 separate observations, each being the mean of five trials.

\section{ANALYSIS OF INFANT HEART RATE RESPONSE}

Analysis was directed toward explaining variation in average postHR responses using the predictors discussed above. Both absolute and percentage of change for the post HR 0-2 and postHR 2-4 periods were examined. Greater success was obtained in analysis of the percentage of change for the posthR 2-4 period (PCHR); hence, the concentration of this paper is on this response measure.

The most significant single predictor of PCHR proved to be preHR. The relationship between PCHR and preHR is shown in Figure $I$. There was a significant negative $(P \leq 0.001)$ correlation between preHR and PCHR $(r=-0.5159)$, indicating that, as preHR increases, PCHR decreases.

PreHR, postconceptional age, and preHR $^{3}$ were selected by stepwise regression (13) as the variables that, in combination, exhibit the greatest value in predicting PCHR. Each variable selected contributed significantly to the regression equation $(P \leq$ 0.05 ). The results of this multiple regression are presented in Table 3 , and, using this solution, the other selected variables do not contribute significantly to the prediction of PCHR. From this equation, it is possible to predict an estimated value for PCHR, given postconceptional age and preHR. Figure 2 demonstrates estimated responses at varying levels of postconceptional age and preHR.

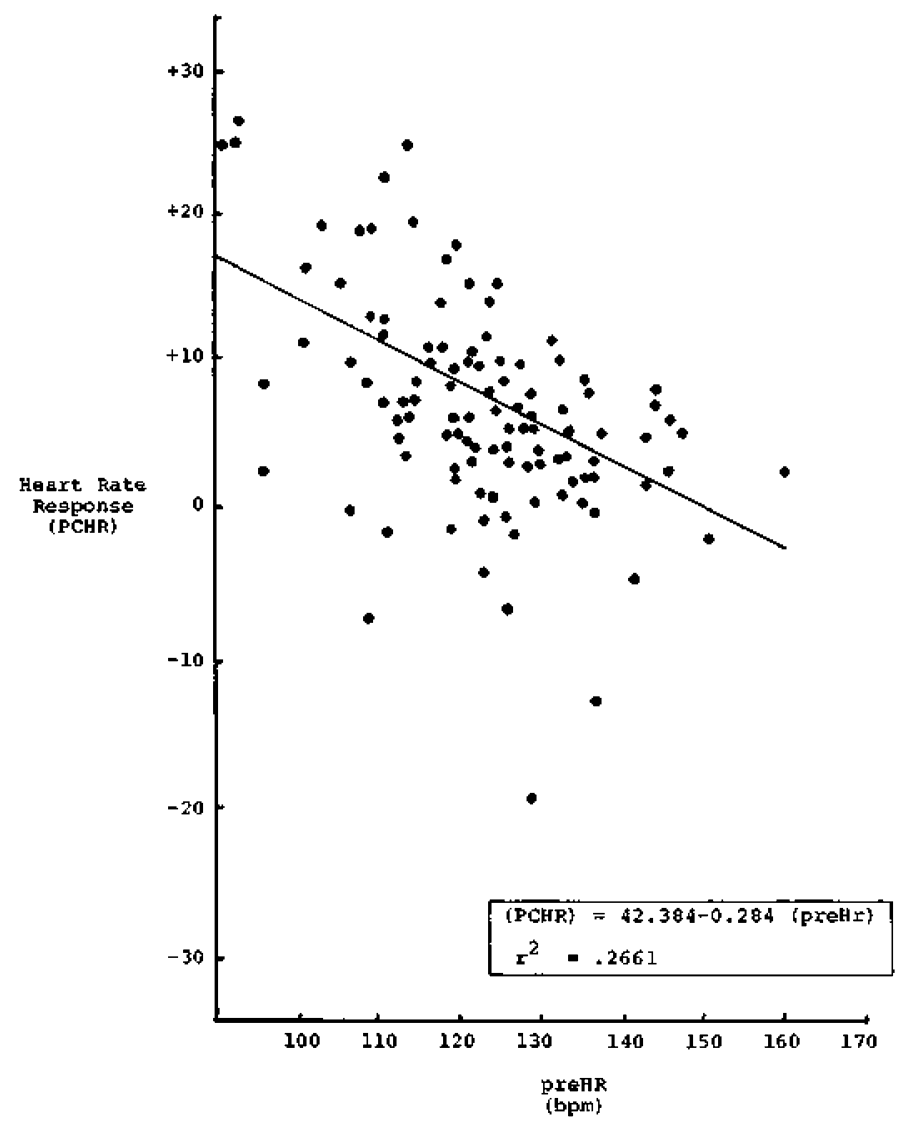

Fig. I. Scaltetgram of hearl rate response as percentage of change (PCHR) vs. prestimulus heart tate (preHR).

Table 3. Summary table for multiple regression analysis

\begin{tabular}{|c|c|c|c|c|c|}
\hline \multicolumn{3}{|c|}{ Variables entering into equation } & \multicolumn{3}{|c|}{ Coefficient } \\
\hline & eptional ag & & & $\begin{array}{c}-0.893 \\
1.29 \times \\
0.204\end{array}$ & $10^{-5}$ \\
\hline Source & SS & $d f$ & $\frac{\text { Anova }}{M S}$ & $F$ & Significance \\
\hline $\begin{array}{l}\text { Regression } \\
\text { Residual }\end{array}$ & $\begin{array}{l}1830.817 \\
4051.971\end{array}$ & $\begin{array}{r}3 \\
106\end{array}$ & $\begin{array}{r}610.272 \\
38.226\end{array}$ & 15.965 & 0.001 \\
\hline
\end{tabular}

' Dependent variable: PCHR $=[($ postHR 2-4 - preHR $) /$ preHR $] \times 100$. $Y$ intercept $=83.39 ;$ multiple $r^{2}=0.3112 ;$ STE of estimate $=6.183$. 